\title{
Avaliação morfológica de plantas jovens de Copaifera langsdorffii Desf. desenvolvidas em diferentes temperaturas
}

\author{
NASCIMENTO, M.E.'; BERTOLUCCI, S.K.V. 2; SANTOS, F.M. 2; SANTOS Jr, J.M. 2; CASTRO, E.M. 2; PINTO, \\ J.E.B.P.* ${ }^{*}$ \\ 1'Instituto de Ciências Agrárias (ICA), Universidade Federal Rural da Amazônia (UFRA). 2Departamento de \\ Agricultura, Setor de Cultura de Tecidos e Plantas Medicinais, Universidade Federal de Lavras (UFLA), Cx.P. \\ 3037, 37200-000, Lavras, MG, Brasil. *jeduardo@dag.ufla.br
}

RESUMO: O principal objetivo da pesquisa foi a avaliação de aspectos da anatomia foliar, da morfologia dos órgãos vegetativos, bem como a produção de biomassa em plantas jovens de Copaifera langsdorffii desenvolvidas sob diferentes temperaturas. Foram coletadas sementes e colocadas para germinar em câmara $\mathrm{BOD}$ a $30^{\circ} \mathrm{C}$. Após trinta dias as plântulas, com o primeiro par de folhas completamente expandidas, foram transplantadas para copos contendo plantimax $\circledast$, e aclimatizadas durante quinze dias em casa de vegetação, quando foram transferidas para BODs com temperaturas $\mathrm{T} 1-15^{\circ} \mathrm{C}, \mathrm{T} 2-25^{\circ} \mathrm{C}, \mathrm{T} 3-35^{\circ} \mathrm{C}$, e a testemunha $(\mathrm{T})$ que permaneceu em casa de vegetação $\left(29^{\circ} \mathrm{C}\right)$. O experimento foi conduzido por um período de 120 dias. Foram observadas diferenças significativas no tamanho e frequência dos estômatos, nas dimensões das cavidades secretoras de óleo, na espessura do mesofilo, nos aspectos morfológicos externos, e na produção de biomassa. A produção de mudas sob temperatura de $25^{\circ} \mathrm{C}$ foi apropriada, sendo a condição onde as plantas tornaram-se mais vigorosas, com morfologia mais uniforme nos órgãos vegetativos e houve maior produção de biomassa seca.

Palavras-chave: copaíba, variações anatômicas, morfologia externa, biomassa seca.

\begin{abstract}
Morphlogical evaluation of Copaifera langsdorffii Desf. saplings grown in different temperatures. The main purpose of this study was to evaluate aspects of leaf anatomy, morphology of vegetative organs and biomass production in Copaifera langsdorffii saplings developed under heat shock treatment. Seeds were collected and germinated in BOD chamber at $30^{\circ} \mathrm{C}$. After thirty days, the seedlings with the first pair of fully expanded leaves were transplanted into cups containing Plantimax ${ }^{\circledR}$, acclimatized for two weeks in a greenhouse and transferred to growth chamber with the temperatures $\mathrm{T} 1-15^{\circ} \mathrm{C}, \mathrm{T} 2-25^{\circ} \mathrm{C}, \mathrm{T} 3-35^{\circ} \mathrm{C}$, and the control $(\mathrm{T})$ remained in a greenhouse $\left(29^{\circ} \mathrm{C}\right)$. The experiment was conducted over a period of 120 days. Significant differences were observed in size and frequency of stomata, size of the oil secretory cavities, thickness of the mesophyll in the external morphology and biomass production. The production of seedlings at $25^{\circ} \mathrm{C}$ is suitable, a condition in which the plants become more vigorous with a more uniform morphology in the vegetative organs and higher production of biomass.
\end{abstract}

Keywords: diesel tree, anatomic variations, external morphology, dry biomass.

\section{INTRODUÇÃO}

Copaifera langsdorffii, nativa do cerrado e de florestas semi-decíduas, devido às suas propriedades medicinais e madeireiras está dentre as espécies que sofrem extrativismo sendo de fundamental importância a obtenção de informações agronômicas e de aclimatização para o cultivo ex situ.

Trata-se de espécie secundária tardia a clímax, com grande plasticidade ecológica, sendo encontrada em várias regiões fitoecológicas, principalmente na região Centro-Oeste e Sudeste em florestas semi-decíduas e no cerrado. Ocorre tanto em áreas de solo fértil e bem drenado, como em áreas de solo muito pobre, ácido e álico do cerrado; é encontrada também em terrenos úmidos, sendo indicada para reflorestamento, arborização e 
recuperação de áreas degradadas (Lorenzi, 2002). Considerando a crescente demanda por informações sobre espécies com potencial para serem implantadas em ambientes degradados e as constantes variações climáticas, é de fundamental importância o conhecimento morfoanatômico e suas variações sob a influência de diferentes condições de temperatura desde os primeiros meses de crescimento, período crítico em que as plântulas encontram-se mais susceptíveis às variações climáticas. Possivelmente essas variações devem provocar alterações a nível das células, dos tecidos, e das estruturas secretoras de óleo, comprometendo a sobrevivência e adaptação das mesmas.

O estudo da anatomia foliar é de grande importância para a compreensão da plasticidade adaptativa de uma espécie submetida a diferentes condições ambientais por está correlacionado com processos de trocas gasosas, assimilação de $\mathrm{CO}_{2}$, e outras características inerentes ao crescimento da planta (Lima, 2006).

A indicação de condições mais adequadas de temperatura é de suma importância para a produção de mudas mais vigorosas, para o melhor estabelecimento no seu ambiente natural, para o reflorestamento e recuperação de áreas degradadas, bem como para a arborização.

Em plantio direto no seu ambiente natural, Copaifera langsdorffii integrou o grupo de espécies florestais com o menor desenvolvimento inicial, cuja sobrevivência foi ameaçada pela matocompetição (Santos Jr, 2000). De acordo com Souza (2002) a taxa de sobrevivência dessa espécie em mata de galeria do Distrito Federal foi menor que 33\% e crescimento inicial lento.

Sobre os efeitos da temperatura no crescimento e anatomia da planta, nada foi encontrado na literatura para a espécie em estudo. Objetivou-se, com esta pesquisa, avaliar a ação de diferentes temperaturas sobre a anatomia foliar e a morfologia dos órgãos vegetativos, na tentativa de identificar a faixa de temperatura mais adequada para a maior produção de biomassa seca e formação de mudas mais vigorosas de $C$. langsdorffi, visando maior sucesso no estabelecimento das mesmas em ambiente natural.

\section{MATERIAL E MÉTODOS}

Sementes de C. langsdorffii de um mesmo lote foram obtidas a partir de frutos maduros coletados em árvores existentes no Campus da UFLA, Lavras-MG, sendo que as exsicatas desses espécimes encontram-se depositadas no herbário ESAL da UFLA, sob os números: 24946, 24947, 24952, 24954 e 24956, correspondentes aos espécimes 1, 2, 3, 4 e 5, respectivamente. Após o beneficiamento, as sementes foram armazenadas em sacos de polietileno semipermeáveis por, aproximadamente, dois meses, em temperatura ambiente até o teste de germinação no Laboratório de Análises de Sementes - LAS/UFLA.

As sementes foram dispostas em recipientes de plástico do Tipo gerbox com areia autoclavada em câmara BOD a $30^{\circ} \mathrm{C}$, onde foram avaliadas durante trinta dias. Plântulas com crescimento uniforme contendo duas folhas completamente expandidas foram transplantadas para recipientes contendo plantmax e deixadas por 15 dias para adaptação ao novo substrato, em casa de vegetação.

$\mathrm{O}$ experimento foi instalado e conduzido no Campus Experimental da Universidade Federal de Lavras - UFLA, Departamento de Agricultura, Laboratório de Cultura de Tecidos e Plantas Medicinais. O delineamento experimental foi inteiramente casualizado - DIC, com testemunha, três tratamentos e cinco repetições, sendo $\mathrm{T}$ a testemunha conduzida em casa de vegetação cuja temperatura variou de $20^{\circ} \mathrm{C}$ a $33,5^{\circ} \mathrm{C}$, com média no período de $29 \pm 2^{\circ} \mathrm{C}$, e os demais com temperatura controlada em câmara BOD regulada: T1, $15 \pm$ $2^{\circ} \mathrm{C}$; T2, $25 \pm 2^{\circ} \mathrm{C}$ e T3, $35 \pm 2^{\circ} \mathrm{C}$. As câmaras foram reguladas com fotoperíodo de 12 horas e as plântulas foram regadas diariamente. O experimento foi instalado em novembro de 2008, e conduzido por 120 dias.

A coleta de material para estudo anatômico foi realizada ao final do experimento, consistindo na retirada de cinco folíolos de cada plântula, onde foram utilizadas as folhas completamente expandidas do segundo nó apical. Para o tratamento T1 foram utilizados folíolos do único par de folhas apicais, uma vez que não produziram folhas novas. Os folíolos foram fixados em FAA e conservados em álcool $70 \%$ aquoso (Kraus \& Arduin, 1997).

Foram realizados testes histoquímicos para se detectar a presença de lipídeos, cristais de oxalato de cálcio, e grãos de amido, a partir de cortes feitos à mão-livre com auxílio de lâmina de aço. Foram preparadas lâminas histológicas semipermanentes, coradas com safrablau, $1 \%$ aquoso, montadas em água glicerinada entre lâmina e lamínulas, e fixadas com esmalte incolor (Kraus \& Arduin, 1997). Para as descrições anatômicas seguiu-se a nomenclatura de acordo com (Apezzatoda-Glória \& Carmello-Guerreiro, 2006).

Os dados avaliados foram: área foliar, altura da planta, comprimento da raiz, biomassa seca da raiz e da parte aérea, freqüência estomática, diâmetro polar e equatorial dos estômatos, relação do diâmetro polar e equatorial dos estômatos, espessura da epiderme adaxial, do parênquima paliçádico, do parênquima esponjoso, da epiderme abaxial e do limbo foliar, diâmetro polar e equatorial

Rev. Bras. PI. Med., Campinas, v.16, n.4, p.931-937, 2014. 
da cavidade secretora e da nervura central.

A contagem de estômatos foi obtida em área de $0,017 \mathrm{~mm}^{2} \mathrm{e}$ as mensurações em $\mu \mathrm{m}$ foi realizada com auxílio do programa Sigma Pro 5.0. A biomassa seca da parte aérea e da parte subterrânea foi obtida a partir de pesagem em balança analítica de quatro dígitos.

Os dados foram submetidos à análise de variância e as médias comparadas pelo teste de Tukey $(p<0,05)$, utilizando o software "SISVAR" versão 4.3 (Ferreira, 2000).

\section{RESULTADOS E DISCUSSÃO}

A temperatura é um componente determinante no clima e seus efeitos estão diretamente relacionados aos processos fisiológicos e bioquímicos que ocorrem no interior da planta. Suas conseqüências tornam-se visíveis na anatomia de células e tecidos, bem como na morfologia dos órgãos, especialmente na folha, onde ocorrem os principais eventos relacionados à fotossíntese.

Decorrido o período de 120 dias, as plantas jovens provenientes dos diferentes tratamentos revelaram variações peculiares e conspícuas nas características morfológicas em todos os órgãos avaliados. O efeito da temperatura influenciou na morfologia em nível foliar caulinar e radicular. Sobretudo o sistema radicular, cuja variação no comprimento da raiz principal foi de $2 \mathrm{~mm}$ a, aproximadamente, $25 \mathrm{~cm}$ (Figura 1 - I e II). As plântulas submetidas à temperatura de $15^{\circ} \mathrm{C}$, praticamente não apresentaram crescimento em altura, sendo o menor crescimento entre os

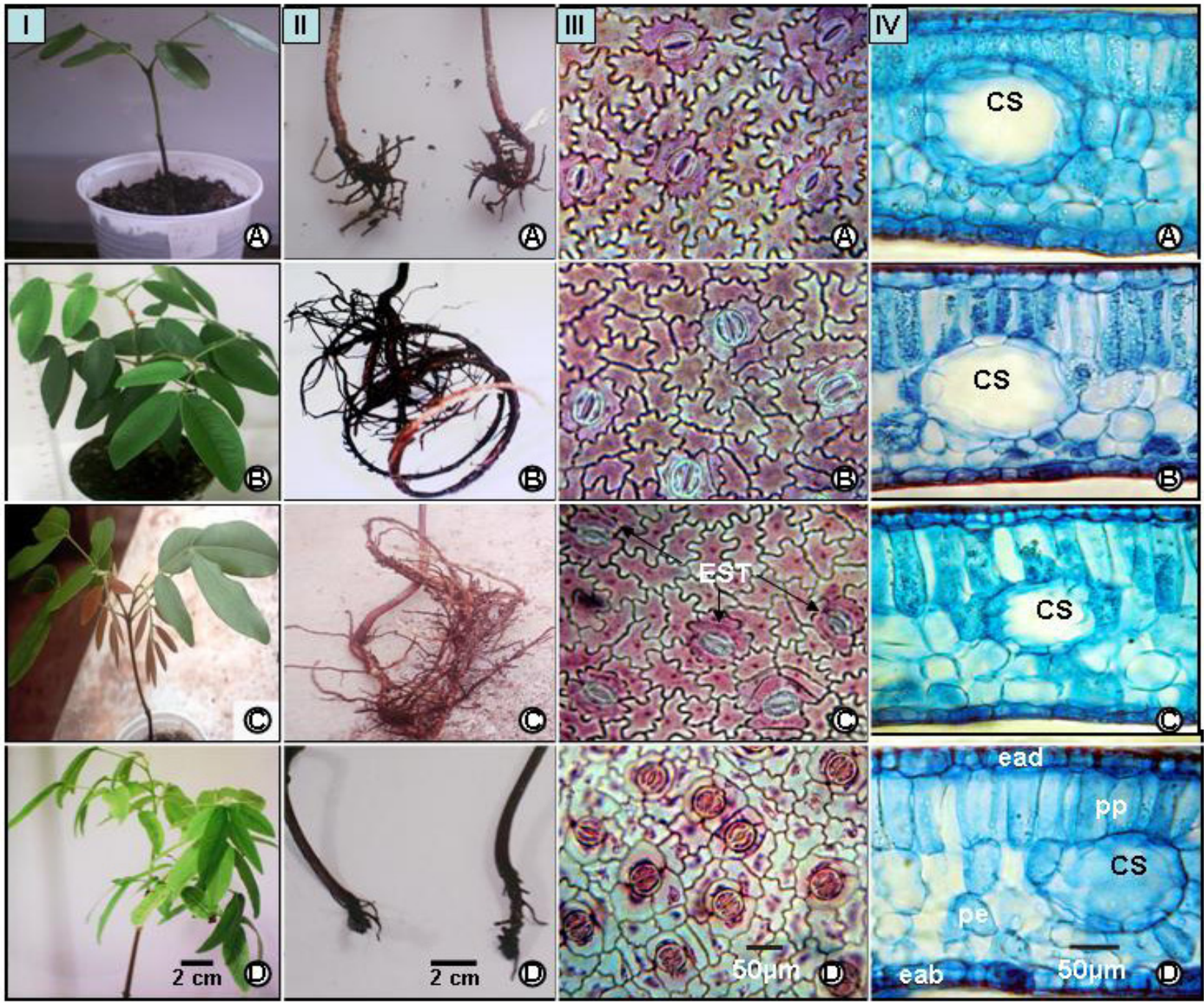

FIGURA 1 (I a IVIA - D). Morfologia e Anatomia foliar de Copaifera langsdorffii sob diferentes temperaturas: A BOD a $15^{\circ} \mathrm{C}$; B - BOD a $25^{\circ} \mathrm{C}$; C - Casa de Vegetação a $29^{\circ} \mathrm{C}$; D - BOD a $35^{\circ} \mathrm{C}$. I - Morfologia externa da parte aérea. II - Morfologia externa da parte subterrânea. III - Superfície foliar com a densidade dos estômatos (Est.). IV - Mesofilo com a epiderme adaxial (ead), parênquima paliçádico (pp), parênquima esponjoso (pe), epiderme abaxial (eab) e as cavidades secretoras de óleo-resina (CS). Venação foliar com as cavidades secretoras de óleo-resina. 
tratamentos, com apenas 1 a $2 \mathrm{~mm}$ de crescimento e sem emissão de novas folhas e ramos. As folhas mais coriáceas e aquelas de coloração em tons de verde mais escuro foram as evidências morfológicas mais destacadas nesse tratamento (Figura 1-I/A).

Das diferentes condições de temperatura, as melhores evidências morfológicas ocorreram nas mudas conduzidas em BOD a $25^{\circ} \mathrm{C}$ (Figura 1 - I/B e II/B) que apresentaram crescimento regular e mais vigoroso, tanto da parte aérea, quanto da raiz, destacando-se, ainda, pela emissão de mais ramos e folhas.

Na casa de vegetação, onde permaneceram as testemunhas sob temperatura média de $29^{\circ} \mathrm{C}$, as plântulas também apresentaram crescimento regular em todos os órgãos, porém com menor emissão de ramos e folhas (Figura 1 - I/C e II/C).

Nas plantas jovens desenvolvidas na BOD de $35^{\circ} \mathrm{C}$ (Figura1 - I/D e II/D) houve destacado crescimento em altura e grande número de novos ramos e folhas. Entretanto, o caule se desenvolveu muito em altura, tornando-se delgado e lateralmente achatado. As raízes atrofiaram e não atingiram crescimento satisfatório.

As folhas não atingiram o desenvolvimento esperado apresentando a menor área foliar, consistência mais membranácea e em tons de verde mais claro, em relação às folhas das plântulas testemunhas (Tabela 1).

A média da altura das plantas jovens apresentou diferença significativa entre os tratamentos, observando que nesses intervalos a altura dessas plantas aumentou de acordo com a elevação da temperatura. Entretanto, as folhas e as raízes não cresceram na mesma proporção, comprometendo assim o vigor e a sobrevivência das plantas. As raízes apresentaram diferenças significativas de acordo com o teste de Tukey e chegaram a medir, em média, $19,42 \mathrm{~cm}$ de comprimento a $25^{\circ} \mathrm{C}$, contrastando com os tratamentos de $15^{\circ} \mathrm{C}$ e $35^{\circ} \mathrm{C}$ (Tabela 1).

As variações no sistema radicular em planta jovem é, certamente, um fator que influencia no seu estabelecimento no campo. Alguns autores têm demonstrado que restrições ao sistema radicular de mudas podem apresentar sérias deformações radiculares após o plantio e menores taxas de crescimento inicial da parte aérea no campo acarretando perdas de produtividade (Novaes et al., 2002; Barroso et al., 2000c; Freitas, 2003; Freitas et al. 2005).

O crescimento do sistema radicular, como os demais órgãos, está diretamente relacionado com as taxas fotossintéticas conforme resultados observados por Lima et al. (2006) para a espécie Cupania vernalis Camb. No presente trabalho, as temperaturas a $15^{\circ} \mathrm{C}$ e a $35^{\circ} \mathrm{C}$ comprometeram fortemente o desenvolvimento de toda planta, constituindo ambiente de estresse para plantas jovens de $C$. langsdorffii.

O tratamento sob BOD $25^{\circ} \mathrm{C}$ favoreceu significativamente a biomassa seca da raiz e da parte aérea das plantas jovens cultivadas nessas condições (Tabela 1). Esse melhor desempenho foi, provavelmente, devido à temperatura mais adequada à realização dos processos fisiológicos e reações bioquímicas indispensáveis ao crescimento da planta.

Em sua organização estrutural interna, as folhas são dorsiventrais e hipoestomáticas. Os estômatos são paracíticos, em sua maioria, podendo ocorrer também o tipo anisocítico e tetracítico sob condições de estresse térmico. A epiderme é formada por uma camada de células cuja face adaxial é recoberta por cutícula mais espessa que cutícula da face abaxial. O parênquima paliçádico é uniestratificado com células alongadas perpendicularmente à epiderme e ricas em grãos de amido. O parênquima esponjoso é característico e ocupa aproximadamente dois terços da espessura da folha. As cavidades secretoras de óleo localizamse no mesofilo, entre esses dois parênquimas, bem como no parênquima fundamental da nervura central. O número de estômatos por área foliar aumentou

TABELA 1. Médias obtidas a partir das variações morfológicas nas folhas, caules, raízes e matéria seca, nos diferentes tratamentos: área foliar $(\mathrm{AF})$ em $\left(\mathrm{cm}^{2}\right)$, altura da plântula $(\mathrm{AP})$ em $(\mathrm{cm})$, comprimento da raiz $(\mathrm{CR})$ em $(\mathrm{cm})$, biomassa seca da raiz (BSR) em $(\mathrm{mg})$ e biomassa seca da parte aérea (BSA) em $(\mathrm{mg})$.

\begin{tabular}{|c|c|c|c|c|c|}
\hline \multirow{2}{*}{ Variáveis } & \multicolumn{5}{|c|}{ Tratamentos com variação de temperatura $\left( \pm 2^{\circ} \mathrm{C}\right)$} \\
\hline & $\mathrm{T}\left(29^{\circ} \mathrm{C}\right)$ & $\mathrm{T} 1\left(15^{\circ} \mathrm{C}\right)$ & $\mathrm{T} 2\left(25^{\circ} \mathrm{C}\right)$ & $\mathrm{T} 3\left(35^{\circ} \mathrm{C}\right)$ & CV (\%) \\
\hline $\mathrm{AF}\left(\mathrm{cm}^{2}\right)$ & $3,26 \mathbf{b}$ & $3,35 \mathbf{b}$ & $5,20 \mathbf{a}$ & $1,43 \mathbf{c}$ & 20,58 \\
\hline $\mathrm{AP}(\mathrm{cm})$ & $12,34 \mathbf{a}$ & $8,98 \mathrm{~b}$ & $14,58 \mathbf{a}$ & $15,56 \mathbf{a}$ & 18,21 \\
\hline $\mathrm{CR}(\mathrm{cm})$ & $19,22 \mathbf{a}$ & $2,82 \mathbf{b}$ & $19,42 \mathbf{a}$ & $3,08 \mathbf{b}$ & 37,07 \\
\hline $\operatorname{BSR}(\mathrm{mg})$ & $0,05 \mathbf{b}$ & $0,05 \mathbf{b}$ & $0,21 \mathbf{a}$ & $0,03 \mathbf{b}$ & 41,11 \\
\hline BSA (mg) & $0,37 \mathbf{b}$ & $0,29 \mathbf{b}$ & $0,54 \mathbf{a}$ & $0,29 \mathbf{b}$ & 26,34 \\
\hline
\end{tabular}

Médias seguidas de mesma letra na linha não diferem estatisticamente pelo teste de Tukey a $5 \%$ de probabilidade.

Rev. Bras. PI. Med., Campinas, v.16, n.4, p.931-937, 2014. 
de acordo com a elevação da temperatura, com exceção das folhas do tratamento a $25^{\circ} \mathrm{C}$, as quais apresentaram frequência estomática ligeiramente menor do que as folhas dos demais tratamentos (Tabela 2).

A freqüência estomática foi a variável foliar mais sensível aos efeitos da temperatura, apresentou diferenças significativas entre os diferentes tratamentos, onde a maior freqüência foi atingida na temperatura mais alta $\left(35^{\circ} \mathrm{C}\right)$, sem contudo, haver uma correlação direta, entre o aumento do número de estômatos e o melhor desempenho no desenvolvimento geral da planta (Tabela 2) e (Figura 1 - III).

Segundo Castro et. al.(2007) a anatomia foliar pode ser altamente modificada por fatores externos. Conforme (Tabela 2), diferenças significativas também foram detectadas nas dimensões estomáticas, em nível de diâmetro polar e equatorial, entre os diferentes tratamentos. Contudo o tamanho dos estômatos, na espécie em estudo, não constitui um fator relacionado diretamente ao desenvolvimento da planta. Isto pode ser confirmado no presente estudo com relação às plântulas testemunhas e a $15^{\circ} \mathrm{C}$, que não apresentaram o maior crescimento, mas apresentaram os maiores estômatos (Tabela 2) e (Figura 1 - III/A e C).

Embora não havendo diferença significativa, o tratamento BOD $25^{\circ} \mathrm{C}$ favoreceu o aumento médio de aproximadamente $23 \mu \mathrm{m}$ na espessura do limbo foliar, com relação ao controle $29^{\circ} \mathrm{C}$ que apresentou espessura de 312,16 $\mu \mathrm{m}$ (Tabela 3).

A espessura da epiderme na face abaxial é ligeiramente diferente, mas não apresentou variação significativa. Porém, na face adaxial, a espessura revelou-se significativamente menor nas plântulas testemunhas (Figura 1 - IV/C).

Quanto aos parênquimas paliçádico, esponjoso e limbo foliar, há evidente variação na espessura sendo, todavia, menor nos tratamentos a $15^{\circ} \mathrm{C}$ e $35^{\circ} \mathrm{C}$ (Figura 1 - IVIA e D), e maiores nos tratamentos a $25^{\circ} \mathrm{C}$ e $29^{\circ} \mathrm{C}$ (Figura $1-$ IV/B e C). Tais resultados estão de acordo com Metcalfe \& Chalk (1983), cujo crescimento e organização da lâmina foliar são altamente influenciados por fatores ambientais, tais como a temperatura, a intensidade de luz, e a disponibilidade de água.

Azevedo (2003) ao realizar estudo comparativo sobre o desenvolvimento foliar de espécies cultivadas in vitro, sala de crescimento, e no campo, ressalta o maior crescimento em espessura do parênquima paliçádico e lacunoso para as plantas de C. langsdorffii cultivadas no campo. De acordo com análise de variância, o maior crescimento em espessura foliar foi estimado para plântulas cultivadas em ambiente controlado, BOD $25^{\circ} \mathrm{C}$, onde as plantas jovens adquirem as melhores condições morfoanatômicas que pode favorecer, posteriormente, melhor adaptação no campo. O diâmetro polar e equatorial das cavidades secretoras

TABELA 2. Média de contagens obtidas na superfície foliar de Copaifera langsdorffii referentes à freqüência estomática (FE), e mensurações micrométricas dos estômatos ( $\mu \mathrm{m})$ : diâmetro polar do estômato (DpE), diâmetro equatorial do estômato (DeE) e relação entre o diâmetro polar e equatorial (RDpe).

\begin{tabular}{|c|c|c|c|c|c|}
\hline \multirow{2}{*}{ Variáveis } & \multicolumn{5}{|c|}{ Tratamentos com variação de temperatura $\left( \pm 2^{\circ} \mathrm{C}\right)$} \\
\hline & TO $\left(29^{\circ} \mathrm{C}\right)$ & $\mathrm{T} 1\left(15^{\circ} \mathrm{C}\right)$ & $\mathrm{T} 2\left(25^{\circ} \mathrm{C}\right)$ & T3 $\left(35^{\circ} \mathrm{C}\right)$ & CV (\%) \\
\hline FE & $19,68 \mathbf{a}$ & $12,36 \mathbf{b}$ & $11,04 \mathbf{b}$ & 21,68 a & 10,72 \\
\hline DpE & $43,72 \mathbf{a}$ & 37,89 b & $35,08 \mathrm{c}$ & $34,85 \mathrm{c}$ & 5,52 \\
\hline DeE & $32,96 \mathbf{a}$ & $26,53 \mathbf{b}$ & 28,68 b & $31,21 \mathbf{a}$ & 4,88 \\
\hline RDpe & $1,34 \mathbf{b}$ & $1,43 \mathbf{a}$ & $1,23 \mathbf{c}$ & $1,12 \mathbf{d}$ & 4,58 \\
\hline
\end{tabular}

Médias seguidas de mesma letra na linha não diferem estatisticamente pelo teste de Tukey a $5 \%$ de probabilidade.

TABELA 3. Espessura média $(\mu \mathrm{m})$ de tecidos da folha de Copaifera langsdorffii: epiderme adaxial (EpAd), parênquima paliçádico (PP), parênquima esponjoso (PE), epiderme abaxial (EpAb) e limbo foliar (LF).

\begin{tabular}{|c|c|c|c|c|c|}
\hline \multirow{2}{*}{ Variáveis } & \multicolumn{5}{|c|}{ Tratamentos com variação de temperatura $\left( \pm 2^{\circ} \mathrm{C}\right)$} \\
\hline & TO $\left(29^{\circ} \mathrm{C}\right)$ & $\mathrm{T} 1\left(15^{\circ} \mathrm{C}\right)$ & $\mathrm{T} 2\left(25^{\circ} \mathrm{C}\right)$ & T3 $\left(35^{\circ} \mathrm{C}\right)$ & CV (\%) \\
\hline EpAd & 19,68 c & $31,20 \mathbf{a}$ & 32,56 a & 23,68 b & 12,95 \\
\hline PP & $144,36 \mathbf{a}$ & $70,64 \mathrm{c}$ & $121,80 \mathbf{b}$ & $79,57 \mathrm{c}$ & 7,97 \\
\hline PE & $231,67 \mathbf{a}$ & 149,28 c & $197,88 \mathbf{b}$ & $142,18 \mathrm{c}$ & 13,07 \\
\hline EpAb & $32,89 a$ & $29,56 \mathbf{a}$ & $30,52 \mathbf{a}$ & 29,16 a & 11,54 \\
\hline LF & $312,16 \mathbf{a}$ & $338,11 \mathbf{a}$ & $345,00 \mathbf{a}$ & $332,81 \mathbf{a}$ & 5,68 \\
\hline
\end{tabular}

Médias seguidas de mesma letra na linha não diferem estatisticamente pelo teste de Tukey a $5 \%$ de probabilidade. 
TABELA 4. Médias obtidas a partir das cavidades secretoras de óleo de Copaifera langsdorffii na folha em um: diâmetro polar (DpCs), diâmetro equatorial (DeCs), e nervura central: diâmetro polar (DpNc) e diâmetro equatorial (DeNc)

\begin{tabular}{|c|c|c|c|c|c|}
\hline \multirow{2}{*}{ Variáveis } & \multicolumn{5}{|c|}{ Tratamentos com variação de temperatura $\left( \pm 2^{\circ} \mathrm{C}\right)$} \\
\hline & TO $\left(29^{\circ} \mathrm{C}\right)$ & $\mathrm{T} 1\left(15^{\circ} \mathrm{C}\right)$ & $\mathrm{T} 2\left(25^{\circ} \mathrm{C}\right)$ & $\mathrm{T} 3\left(35^{\circ} \mathrm{C}\right)$ & CV (\%) \\
\hline DpCs & $211.60 \mathrm{a}$ & $133.60 \mathrm{~b}$ & 200.45 a & $123.41 \mathrm{~b}$ & 14,31 \\
\hline DeCs & 232.10 a & $176.52 \mathbf{b}$ & $206.72 \mathrm{a}$ & $133.33 \mathbf{b}$ & 21,63 \\
\hline DpNc & 307.25 a & 149.53 b & 155.26 b & $133.74 \mathbf{b}$ & 8,73 \\
\hline DeNc & 331.90 a & $193.01 \mathrm{cb}$ & 225.62 b & 160.69 b & 14,37 \\
\hline
\end{tabular}

Médias seguidas de mesma letra na linha não diferem estatisticamente pelo teste de Tukey a $5 \%$ de probabilidade

de óleo apresentou diferenças significativas, de acordo com o teste de Tukey, conforme (Tabela 4). Os tratamentos a $29^{\circ} \mathrm{C}$ e a $25^{\circ} \mathrm{C}$ apresentaram os maiores diâmetros polar e equatorial das cavidades secretoras de óleo e, nas temperaturas a $35^{\circ} \mathrm{C}$ e a $15^{\circ} \mathrm{C}$ foram observados os menores diâmetros (Tabela 4). Quanto aos feixes vasculares na nervura central, estes se mostraram ligeiramente diferentes quanto ao diâmetro polar e equatorial, com destaque apenas para o tratamento a $29^{\circ} \mathrm{C}$ (Tabela 4 ).

De acordo com Larcher (2000), o estresse é um desvio significativo das condições ótimas para a vida; ou seja, é tudo que desvia a planta das condições ideais de crescimento e desenvolvimento, tanto para mais como para menos. No presente trabalho essa situação de estresse foi verificada na temperatura de $15^{\circ} \mathrm{C}$ e $35^{\circ} \mathrm{C}$, cujos efeitos foram percebidos a nível morfológico, anatômico, e na biomassa seca.

Para um determinado fator estressante, cada planta tem um limite de tolerância correspondente, podendo variar entre espécies, ou entre diferentes genótipos de uma mesma espécie, e entre fases fenológicas de um mesmo genótipo (Samallwood, 1999). Para a espécie em estudo, o efeito da temperatura exerceu transformações profundas e uniformes para, aproximadamente, $90 \%$ das plantas jovens em cada tratamento, especialmente nas BODs de 15 e $35^{\circ} \mathrm{C}$.

Apesar da paralisação do crescimento das plantas jovens conduzidas a $15^{\circ} \mathrm{C}$, e do excessivo crescimento em altura das plantas jovens conduzidas a $35^{\circ} \mathrm{C}$, essas permaneceram vivas após o período de 120 dias, evidenciando ampla plasticidade anatômica da espécie. De acordo com St. John \& Christiansen (1976) a ocorrência de frio após emissão da radícula e nos primeiros estádios de desenvolvimento afeta o crescimento inicial e causa: vazamento de metabólitos através da membrana; interferência na produção de ATP; decréscimo na síntese de proteínas e de ácido nucléico; e alterações no tamanho e forma das primeiras folhas. Nas plantas conduzidas em BOD de $15^{\circ} \mathrm{C}$, não houve emissão de novas folhas e paralisação no crescimento das raízes. O pequeno tamanho das folhas, a forma e a coloração das mesmas, foi o efeito mais evidente na BOD de $35^{\circ} \mathrm{C}$, o que, possivelmente, pode indicar a ocorrência dos mesmos eventos supra citados para a espécie em estudo.

Segundo o mesmo autor, em plantas tolerantes ao frio, tem sido encontrado cálcio bloqueando a exudação de solutos de raízes; possivelmente esse efeito tenha ocorrido nas raízes das plântulas conduzidas em $\mathrm{BOD}$ a $15^{\circ} \mathrm{C}$, onde, de acordo com os teste histoquímicos, foram identificados cristais de oxalato de cálcio em grande quantidade próximo aos feixes vasculares nas raízes.

Para algodoeiro, a temperatura acima de $32^{\circ} \mathrm{C}$ diminuiu a fotossíntese bruta, o tamanho da maçã, e o comprimento de fibra, e tornou mais lento o enchimento das maçãs (Yfoulis \& Fasoulas, 1978). De acordo com Reddy et al.(1992) acima de $35^{\circ} \mathrm{C}$, foi afetado o número de flores e de frutos formados. Para a espécie em estudo, por tratar-se de plântulas nos primeiros meses de crescimento, os efeitos principais foram manifestados nas folhas, no aumento do número de estômatos, na diminuição da espessura do parênquima paliçádico, esponjoso e do limbo foliar em geral, afetando ainda na diminuição do tamanho dos estômatos e das cavidades secretoras de óleo.

De acordo com Hall (1992), sob temperaturas elevadas, foi observado o incremento de biomassa, aumento na taxa de transpiração, alongamento excessivo de entrenós, auto-sombreamento e alterações na partição de fotoassimilados em caupi (Vigna unguiculata (L.) Walp.). Efeitos semelhantes foram observados no presente trabalho, onde o alongamento dos entrenós e achatamento lateral do caule tornou-se bem visível nas plantas jovens conduzidas em BOD a $35^{\circ} \mathrm{C}$.

Diante dos resultados obtidos, nas condições do experimento, pode-se concluir que:

Trata-se de uma espécie com ampla plasticidade anatômica. Os ambientes controlados

Rev. Bras. PI. Med., Campinas, v.16, n.4, p.931-937, 2014. 
com diferentes faixas de temperatura podem proporcionar profundas alterações na anatomia e na morfologia foliar de Copaifera langsdorffii. Nas temperaturas extremas, as plantas jovens expressaram sinais de estresse térmico pela paralisação do crescimento na temperatura de $15^{\circ} \mathrm{C}$ e pelo crescimento desregulado na temperatura de $35^{\circ} \mathrm{C}$. A submissão das plantas jovens à ambientes controlados com temperatura de $25^{\circ} \mathrm{C}$ pode ser utilizada como estratégia para a produção de mudas com boas condições para o plantio no campo.

\section{AGRADECIMENTO}

Ao Conselho Nacional de Desenvolvimento Científico e Tecnológico (CNPq), a Coordenação de Aperfeiçoamento de Pessoal de Nível Superior (CAPES) e à Fundação de Amparo à Pesquisa de Minas Gerais (FAPEMIG) pelo apoio financeiro, bolsa de estudo e produtividade.

\section{REFERÊNCIA}

APPEZZATO-DA-GLÓRIA, B.; CARMELLOGUERREIRO. S.M. Anatomia Vegetal. 2 ed. Atual. Viçosa: Ed. UFV. 2006. 438p.

BARROSO, D.G.; CARNEIRO, J.G. de A.; NOVAES, A.B.; LELES, P.S. dos S. Efeitos do recipiente sobre o desempenho pós-plantio de Eucalyptus camaldulensis e E. urophylla. Revista Árvore, Viçosa, MG, v. 24, n. 3, p. 291-296, 2000c.

CASTRO, E.M.; PINTO, J.E.B.P.; SOARES, A.M.; MELO, H.C.; BERTOLUCCI, S.K.V.; VIEIRA, C.V.; JÚNIOR, E.C.L. Adaptações anatômicas de folhas de Mikania glomerata Sprengel (Asteraceae), em três regiões distintas da planta, em diferentes níveis de sombreamento. Revista Brasileira de Plantas Medicinais, Botucatu, v. 9, n. 2, p. 8-16, 2007.

FERREIRA, D.F. Sisvar 4.3 - Sistema de análises estatísticas. Lavras, UFLA, 2000.

FREITAS, T.A.S. Sistemas de blocos prensados para produção de mudas clonais de eucalipto. 2003. 115p. Dissertação (Mestrado - Área de Concentração em Produção Vegetal) - Departamento de Agricultura, Universidade Estadual do Norte Fluminense - Darcy Ribeiro, Campos dos Goytacazes, RJ.

FREITAS, T.A.S.; BARROSO, D.G.; CARNEIRO, J.G. de A.; PENCHEL FILHO, R.M.; LAMÔNICA, K.R.; FERREIRA, D. de A. Desempenho radicular de mudas de eucalipto produzidas em diferentes recipientes e substratos. Revista Árvore, Viçosa, MG, v. 29, n. 6, p. $853-861,2005$.
HALL, A.E. Breeding for heat tolerance. Plant Breeding Reviews, California, v. 10, n. 1, p. 129-168, 1993.

KRAUS, J.E.; ARDUIN, M. Manual básico de métodos em morfologia vegetal. Seropédica: EDUR, 1997. $198 p$.

LARCHER, W. Ecofisiologia vegetal. São Carlos, Rima Artes e Textos: 2000. $531 \mathrm{p}$.

LIMA, E.C.; ALVARENGA, A.A.; CASTRO, E.M.; VIEIRA, C.V.; BARBOSA, J.P.P.A.D. Aspectos fisioanatômicos de plantas jovens de Cupania vernalis Camb. Submetidas a diferentes níveis de sombreamento. Revista Árvore, Viçosa, MG: v. 30, n. 1, p. 33-41, 2006.

LORENZI, H. Árvores Brasileiras: Manual de Identificação e Cultivo de Plantas Arbóreas Nativas do Brasil. 2. ed. Nova Odessa, São Paulo, Instituto Plantarum: v. 1, 2002, $351 \mathrm{p}$.

METCALFE, C.R. \& CHALK, L. Anatomyof the Dicotyledons.2. ed. Oxford, Clarendon Press: v. 1, 1983. 276 p.

METCALFE, C.R. \& CHALK, L. Anatomy of Dicotyledons. 2. ed. Oxford, Clarendon Press: v. 2, 1989. 297 p.

NOVAES, A.B.; CARNEIRO, J.G.A.; BARROSO, D.G.; LELES, P.S.S. Comportamento de mudas de Pinus taeda produzidas em raiz nua e em dois tipos de recipientes, 24 meses após o plantio. Floresta, Curitiba, v. 31, p. 62-71, 2002.

REDDY, K.R.; HODGES, H.F.; REDDY, V.R. Temperature effects on cotton fruit retention. Agronomy Journal, New York, v. 84, p. 26-30, 1992.

SAMALLWOOD, M.F.; CALVERT, C.M. \& BOWLES, D.J. Plant responses to environmental stress. New York: Bios Scientific Publishers Limited, 1999. 224 p.

SANTOS JUNIOR, N.A. Estabelecimento inicial de espécies florestais nativas em sistema de semeadura direta. 2000. 96 p. Dissertação (Mestrado -Engenharia Florestal) - Universidade Federal de Lavras, Lavras, MG.

SIQUEIRA, G.C.L.; MENEZES, M.; SIQUEIRA, S.L.; SILVA, J.F. da; ALVAREZ RIVERA, G.R.; VICENTE, C.A.R.; NIETO, M.D. Copaíba: produtos potenciais da Amazônia. MMA/SUFRAMA/SEBRAE/GTA, Brasília, 1998. 28 p.

SOUZA, C.C. Estabelecimento e Crescimento Inicial de Espécies Florestais em Plantios de Recuperação de Matas de Galeria do Distrito Federal. 2002. 91 p. Dissertação (Mestrado em Ciências Florestais) Universidade de Brasília, Brasília, DF.

ST.JOHN, J.B.; CHRISTIANSEN, M.N. Inhibition of linolenic acid synthesis and modification of chilling resistance in cotton seedlings. Plant Physology, v. 57, p. 257-259, 1976. In TAIZ, L.; ZEIGER, E. Plant physiology. 2. ed. 1976.

YFOULIS, A.; FASOULAS, A. Role of minimum and maximum environmental temperature on maturation period of the cotton boll. Agronomy Journal, Madison, v. 70 , p. $421-425,1978$. 